\title{
TEKNOLOGI VIRTUAL REALITY UNTUK MEDIA INFORMASI KAMPUS
}

\author{
Herman Thuan To Saurik ${ }^{1}$, Devi Dwi Purwanto ${ }^{2}$, Jeremiah Irawan Hadikusuma ${ }^{3}$ \\ ${ }^{1}$ Program Studi Desain Komunikasi Visual Sekolah Tinggi Teknik Surabaya \\ ${ }^{2,3}$ Program Studi Sistem Informasi Sekolah Tinggi Teknik Surabaya \\ Email: 'thuan@ stts.edu, ${ }^{2}$ devi@ stts.edu, ${ }^{3}$ jerespoor@gmail.com
}

(Naskah masuk: 13 November 2018, diterima untuk diterbitkan: 18 Desember 2018)

\begin{abstract}
Abstrak
Media informasi terus berkembang dengan hadirnya teknologi yang semakin membawa kemudahan bagi manusia agar sebuah pesan dapat tersampaikan dengan baik, tepat, cepat dan bermanfaat. Salah satu perkembangan teknologi pada mobile yang mendukung media informasi adalah Virtual Reality (VR). VR menjadi alternatif dikarenakan penyajian pesan yang interaktif dengan memberikan lingkungan yang imersif sebagai daya tarik pengguna. Media informasi pada lingkungan gedung kampus menjadi salah satu topik yang dibahas dalam penelitian ini. Permasalahan yang didapat adalah bagaimana memberikan sebuah lingkungan gedung kampus yang imersif kepada pengguna dengan penanganan media informasi yang dirancang agar dapat disampaikan secara interaktif dan komunikatif. Penelitian ini mengambil studi kasus gedung yang terdapat pada salah satu perguruan tinggi swasta di Surabaya. Tiap gedung memiliki ruang di tiap lantai yang menjadi pusat administrasi, kegiatan perkuliahan, ruang serbaguna, ruang dosen, dan ruang kegiatan mahasiswa. Tujuan penelitian ini adalah menghasilkan sebuah aplikasi VR dengan output mobile untuk gedung kampus beserta tata ruang secara imersif dan penanganan konten informasi dinamis didalamnya. Penanganan konten informasi dinamis dapat diwujudkan dengan penggunaan gyroscope untuk pergerakan VR dan konten penyedia informasi untuk teks dan gambar.
\end{abstract}

Kata kunci: Denah Interaktif 3D, Virtual Reality, Media Informasi, Aplikasi Mobile

\section{Virtual Reality Technology for Campus Media Information}

\begin{abstract}
Media information continues to grow with the presence of technology that increasingly brings convenience for humans to a message can be delivered properly, precisely, quickly and useful. One of the technological developments in mobile that support information media is Virtual Reality (VR). VR is an alternative because of the interactive messaging presentation by providing an immersive environment as the user's appeal. The information media in the campus building is one of the topics discussed in this research. Problems gained is how to provide an immersive campus building environment to the user with the handling of information media designed to be delivered interactively and communicative. This research takes a case study of the building contained in private universities in Surabaya. Each building has rooms on each floor that become the administrative center, study activities, multipurpose room, lecture room and student activity room. The purpose of this study is to produce an immersive VR application with mobile output for campus buildings, and handling dynamic information content. Handling dynamic information content is realized through the use of gyroscopes for VR movement and information provider content for text and images.
\end{abstract}

Keywords: Interactive 3D Plan, Virtual Reality, Media Information, Mobile Application

\section{PENDAHULUAN}

Kemajuan teknologi yang semakin berkembang membuat sebuah media informasi kini beralih ke dalam media Virtual Reality (VR) (Moura, 2017). Virtual Reality adalah pemunculan gambar-gambar tiga dimensi yang dibuat komputer sehingga terlihat nyata dengan bantuan sejumlah peralatan tertentu, yang menjadikan penggunanya seolah-olah terlibat langsung secara fisik dalam lingkungan tersebut (Puto, 2015). Virtual Reality menjadi konsep berinteraksi yang cukup mudah digunakan seiring dengan perkembangan teknologi mobile yang dapat difungsikan sebagai media tersebut (Pius, 2017). Saat ini hanya dengan bermodalkan mobile dan 
Google Cardboard dapat menampilkan konten VR (Cardboard, 2014). Beberapa peranan VR seperti simulasi, pembelajaran interaktif, promosi, dan permainan kini semakin banyak dikembangkan (Dimas\& Firly, 2017; Zikky, 2016). Dengan potensi yang telah ada tersebut maka penelitian ini memanfaatkan teknologi VR dalam menghasilkan media informasi pada gedung kampus untuk pengguna.

Objek Penelitian yang digunakan terletak pada salah satu perguruan tinggi swasta di Surabaya. Terdapat 5 gedung utama yaitu: gedung E , gedung $\mathrm{U}$, gedung $\mathrm{N}$, gedung $\mathrm{B}$ dan gedung $\mathrm{L}$. Tiap gedung memiliki ruang ditiap lantai yang menjadi pusat administrasi, kegiatan perkulihan, ruang serbaguna, ruang dosen dan ruang kegiatan mahasiswa. Terdapat Informasi papan petunjuk dan poster denah terdapat di lokasi pengumuman yang ada di lantai 1 . Pemanfaatan papan petunjuk yang diberikan seperti sarana dan fasilitas pada gedung atau ruang belum memberikan gambaran ekplorasi dan cenderung pasif. Apabila gedung kampus dieksplorasi secara lebih mendalam, informasi tentang ruang, petunjuk lokasi, dan gambar visual dapat disampaikan secara lengkap. Namun, selama ini pengunjung hanya memperoleh informasi melalui tulisan atau penjelasan yang diperoleh dari papan informasi dan selebaran (brosur).

Tujuan penelitian ini adalah menghasilkan sebuah aplikasi VR dengan output mobile untuk gedung kampus beserta tata ruang secara imersif dan penanganan konten informasi dinamis didalamnya.

\section{SUMBER PUSTAKA/RUJUKAN}

Berikut akan dijabarkan sumber pustaka pada penelitian ini yaitu media informasi dan virtual reality, pembahasan dapat dilihat pada subbab berikut

\subsection{MEDIA INFORMASI}

Media informasi merupakan alat untuk mengumpulkan serta menyusun kembali sebuah informasi sehingga menjadi bahan yang bermanfaat bagi penerima informasi. Komponen strategi penyampaian yang dapat dimuati pesan yang akan disampaikan kepada pembelajar bisa berupa alat, bahan, dan orang (Degeng, 1989:142). Media informasi merupakan "alat-alat grafis, fotografis atau elektronis untuk menangkap, memproses, serta menyusun kembali informasi visual". Jenis-jenis Media Informasi sebagai alat tepat sasaran harus dapat dengan baik tersampaikan kepada target sasaran, sehingga bisa bermanfaat bagi pembuat maupun penerima informasi (Jefkins\& Frank, 1997). Media informasi dapat dibagi menjadi beberapa kelompok yaitu :

- Media Lini Atas, media yang tidak langsung bersentuhan dengan target audience serta jumlahnya terbatas tetapi jangkauan target yang luas, seperti iklan televisi, iklan radio, billboard.

- Media Lini Bawah, media iklan yang tidak disampaikan melalui media massa serta jangkauan target hanya ditekankan pada suatu daerah atau titik, seperti flayer, poster, sign system.

- Media Cetak dapat berupa majalah, flayer, poster, pamphlet, spanduk

- Media Elektronik, Media ini disampaikan melalui radio, ponsel, kamera, dan internet.

\subsection{VIRTUAL REALITY}

Virtual Reality adalah pemunculan gambargambar tiga dimensi yang dibuat komputer sehingga terlihat nyata dengan bantuan sejumlah peralatan tertentu, yang menjadikan penggunanya seolah-olah terlibat langsung secara fisik dalam lingkungan tersebut (Moura, 2017). Virtual Reality membutuhkan perangkat yang dirancang untuk tujuan tertentu dalam teknologi ini, sehingga mampu menjadikan orang yang merasakan dunia maya terkecoh dan yakin bahwa yang dialaminya adalah nyata. Beberapa perangkat yang digunakan antara lain: Force balls/tracking balls, Controller wands, Voice recognition, Headset, Joysticks / gamepad, Data gloves, Treadmills, Motion trackers/bodysuits.

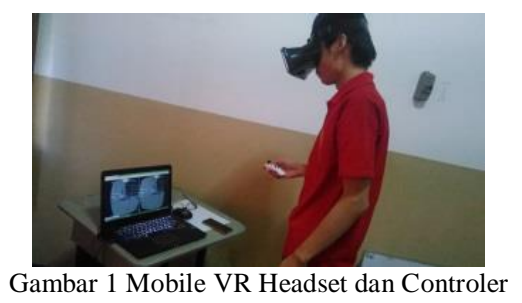

Saat berada dalam lingkungan virtual, pengguna akan merasa seolah menyatu dengan dunianya dan dapat berinteraksi dengan objek-objek yang ada di sana. Hal ini disebut dengan telepresence. Telepresence diartikan sebagai pengalaman keberadaan seseorang terhadap lingkungan melalui sebuah media (Moura, 2017). Penggunaan istilah telepresence digunakan untuk jenis komunikasi yang menggunakan media dalam tujuannya menghadirkan persepsi. Steuer (1993) menjelaskan dua indikator utama dalam menjabarkan komunikasi melalui media dalam kaitannya terhadap telepresence :

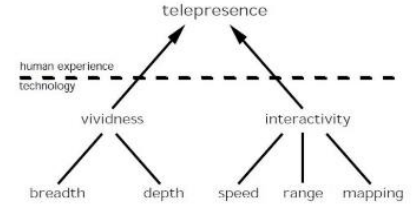

Gambar 2. Indikator dalam Telepresence Sumber : Steuer (Defining Virtual Reality: Dimensions Determining Telepresence, 1993)

\subsubsection{Vividness}

Vividness merupakan salah satu indikator dari sebuah media yang dapat meningkatkan persepsi. 
Vividness berarti kualitas representasional dari lingkungan yang termediasi diurai dari fitur formalnya, dimana lingkungan tersebut memberikan informasi melalui indra. Menurut Steuer (1993), ada dua komponen dalam perasaan telepresence atau "melebur" ini, yang disebut:

- Depth of information, merupakan banyaknya kualitas data yang ditansfer demi menciptakan lingkungan VR( resolusi, ketajaman gambar).

- Breadth of information, merupakan seberapa besar indera pengguna dimanipulasi, umumnya pada penglihatan dan pendengaran.

\subsubsection{Interactivity}

Interaktifitas merupakan penjelasan tentang pada bagian mana pengguna dapat berpartisipasi untuk merubah bentuk dan isi dari sebuah media. Tiga faktor yang berkontribusi kepada interaktifitas:

- Speed of interaction, or response time: kecepatan, yang mengacu pada tingkat di mana input dapat berasimilasi dengan lingkungan termediasi.

- Range : Kisaran, yang mengacu pada jumlah kemungkinan tindakan pada waktu tertentu.

- Mapping : pemetaan, yang mengacu pada kemampuan sistem untuk memetakan kontrol untuk perubahan lingkungan yang termediasi secara alami dan dapat diprediksi.

\section{METODE PENELITIAN}

Alur penelitian diawali dengan melakukan tahap sketsa terhadap salah satu gedung kampus. Gedung kampus yang digunakan berlantai 7 dengan memiliki beberapa ruang administrasi, perkuliahan dan perpustakaan.Sketsa gedung kampus dilakukan dengan melakukan observasi gedung kampusdanpengambilan foto. Dari hasil sketsa kemudian dilakukan permodelan $3 \mathrm{D}$ dengan menggunakan software 3Ds Max untuk menghasilkan file FBX.

Pada tahap selanjutnya file FBX dimport kedalam game engine Unity untuk menghasilkan object yang akan diaplikasikan kedalam media VR menggunakan librarySDK google cardboard. Pengaturan konten informasi yang digunakan sebagai media informasi gedung dan ruang menggunakan file JSON. Penanganan konten yang dinamis menggunakan file JSON dibuat menggunakan website admin. Implementasi yang dilakukan pada object 3D dan file JSON sebagai kebutuhan informasi gedung dan ruang kemudian menghasilkan aplikasi VR yang dipublish pada mobile. Gambar 3 merupakan Diagram Alur Pengembangan dalam penelitian yang dilakukan.

Ujicoba kelayakan dilakukan guna mengetahui tampilan dunia VR, interaksi giroscope dan penempatan konten informasi untuk gedung dan ruang. Ujicoba dilakukan di mobile android dengan ukuran layar 5,5 inch yang memiliki fitur giroskop.

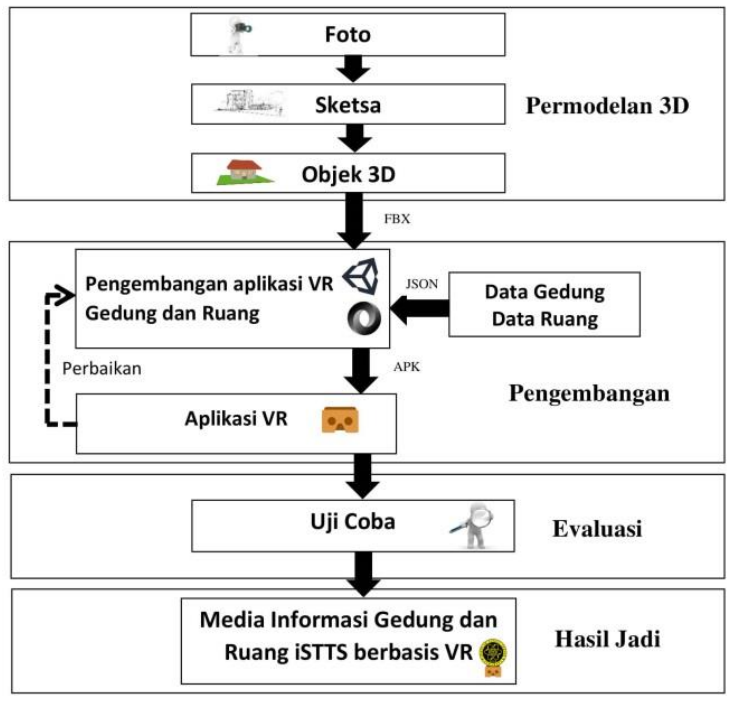

Gambar 3. Diagram Alur Pengembangan Aplikasi

\section{HASIL DAN PEMBAHASAN}

Hasil yang telah dicapai dalam pembuatan media informasi untuk gedung kampus adalah sebagai berikut

\subsection{Permodelan Gedung dan Ruang}

Dalam melakukan perancangan desain gedung dan ruang, sebagai bahan studi kasus menggunakan Gedung Eagle STTS yang berlokasi di Ngagel Jaya Tengah 73-77 Surabaya, gedung setinggi 7 lantai ini memiliki beberapa ruang dan fasilitas didalam penunjang media informasi. Pada tahap rancangan desain gedung dan ruang dibuat dalam sketsa desain gambar 2D untuk bagian eksterior dan interior gedung E yang dapat dilihat pada Gambar 4A.

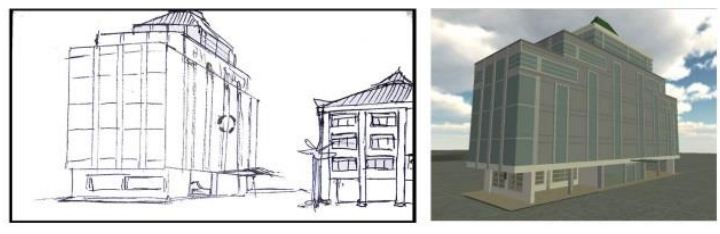

Gambar 4A. Permodelan 3D Gedung

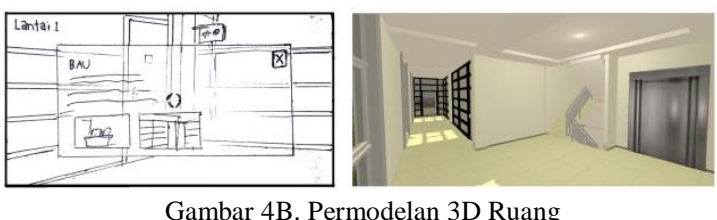

Pada Gambar 4B dilakukan pembuatan area target untuk menampilkan konten dalam interior ruang dengan menggunakan bentuk geometri sederhana yang nantinya digunakan sebagai area untuk kemunculan foto ruangan, deskripsi ruangan,kapasitas dan status.

\subsection{Pergerakan Kamera dan Navigasi}

Fitur pergerakan kamera dan navigasi merupakan fitur utama yang berkaitan langsung dengan proses 
eksplorasi gedung. Pengguna dapat berjalan maju ke depan dengan cara sedikit menghadapkan kepala dan berhenti berjalan ketika mengangkat kepala kembali. Dengan cara ini pengguna VR tidak membutuhkan tombol pada controller untuk dapat berjalan melakukan eksplorasi pada VR. Pergerakan berjalan ini mendeteksi angle dengan bantuan sensor pada giroscope perangkat mobile. Pada bagian ini terdapat area untuk media informasi yang diletakan dalam bentuk panel seperti terlihat pada Gambar 5 .

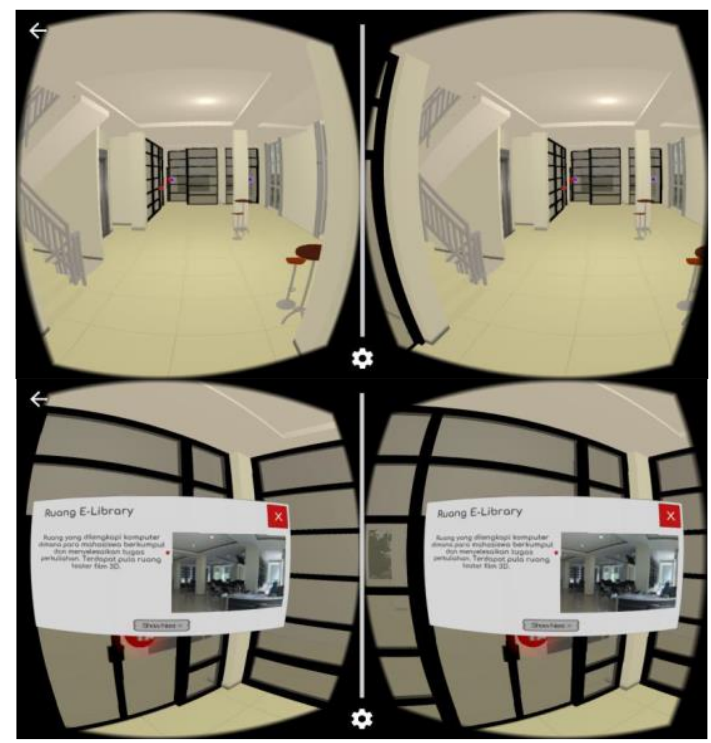

Gambar 5. Tampilan Informasi Ruang

Pembuatan area target yang didesain dalam ruangan berupa bentuk geometri sederhana merupakan daerah yang nantinya digunakan untuk menampilkan konten informasi seperti yang terlihat pada Gambar 5. Guna menyediakan fitur bagi pengguna untuk berpindah atau mencari gedung tanpa menggunakan controller dilakukan dengan mengarahkan posisi kamera VR 30 derajat dari arah pandang kebawah, penggunaan angka derajat ini dapat disesuaikan untuk mengatur gerak berjalan pengguna dengan didukung oleh fitur gyroscope pada mobile dengan menggunakan GoogleVR SDK. Gambar 6 merupakan hasil uji coba aplikasi VR gedung kampus.

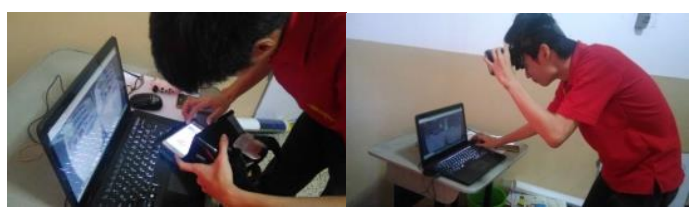

Gambar 6. Uji coba aplikasi

\subsection{Media Informasi Gedung dan Ruang}

Gambar gedung dan ruangan berserta deskripsi text yang merupakan konten informasi untuk aplikasi VRdibuat dengan file JSON. File JSON tersimpan dalam server dan akan diunduh ke dalam local storage mobile saat aplikasi dijalankan pertama kali. Untuk membuat konten yang dinamis maka perubahan dan pembaharuan informasi gedung dan ruang menggunakan website. Gambar 7 merupakan tampilan fitur admin untuk melakukan update konten.

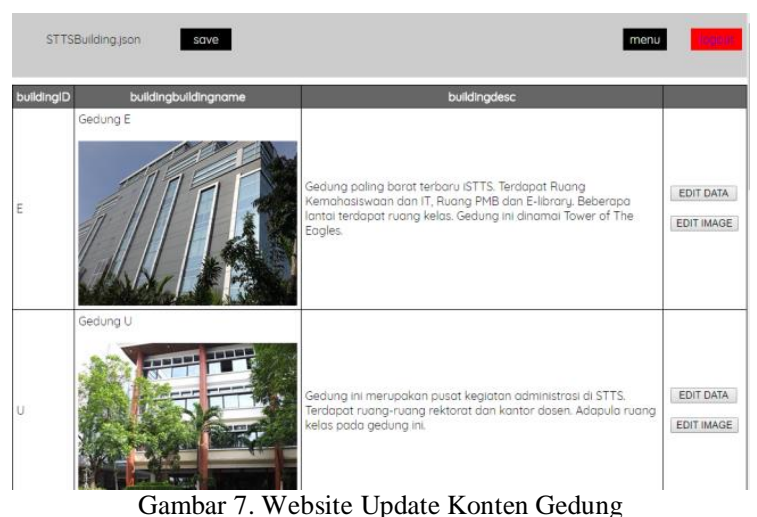

\subsection{Uji Coba Kelayakan Aplikasi}

Uji coba kelayakan aplikasi dilakukan oleh peneliti menggunakan perangkat untuk menjalankan program sebagai berikut :

- Smartphone 1

Processor : Snapdragon 430 Octa Core | Adreno

505 GPU, RAM : 3 GB, OS : Android 6.0

Marshmallow

- Smartphone 2

Processor : Exynos 5 Octa 5420 | Mali-T628 MP6 GPU, RAM : 3 GBOS : Android 5.0 Lollipop

- Smartphone 3

Processor : Snapragon 425 | Adreno 308 GPU

RAM : 2 GB, OS : Android 5.0 Lollipop

Pengujian aplikasi mobile VR yang dilakukan bertujuan untuk mengetahui performa dan kinerja dari aplikasi menggunakan perangkat dengan spesifikasi yang disebutkan di atas. Dengan 3 perangkat yang memiliki sensor gyroscope, hasil yang didapat adalah aplikasi VR berjalan cukup mulus dengan menggunakan smart phone tipe 1 dan 2 dimana saat menampilkan scene yang memiliki banyak objek masih bisa ditangani dengan baik tanpa lag yang berarti. Sedangkan pada smartphone tipe 3 ditemukan sedikit lag saat membuka scene kompleks halaman namun memiliki nilai FPS yang layak. Ketiga perangkat yang telah terhubung jaringan internet tersebut dapat melakukan download data dari server, menyimpan ke storage, refresh data, hingga menampilkan informasi tanpa kendala. Aplikasi akan memakan RAM pada device sebanyak sekitar 100 MB. Aplikasi membutuhkan perangkat minimal memiliki RAM 2 GB untuk dapat menjalankan aplikasi dengan baik dan lancar.

Berdasarkan hasil uji coba dari evaluasi yang dilihat pada tabel 1, maka dilakukan evaluasi aplikasi hasil, dilihat dari aspek rekayasa perangkat lunak dan aspek komunikasi. Dimana responden menilai aspek rekayasa perangkat lunak sangat baik 
dengan persentase $51 \%$ dan aspek komunikasi visual sangat baik dengan persentase $48 \%$.

Tabel 1. Evaluasi Aplikasi

\begin{tabular}{|c|c|c|c|c|c|c|}
\hline $\begin{array}{l}\mathbf{N} \\
\mathbf{o}\end{array}$ & $\begin{array}{l}\text { Aspek Rekayasa } \\
\text { Perangkat Lunak }\end{array}$ & 5 & \multicolumn{3}{|c|}{ ( dalam \% ) } & \\
\hline 1. & $\begin{array}{l}\text { Menurut anda, } \\
\text { bagaimana } \\
\text { tingkat kemudahan } \\
\text { penggunaan aplikasi VR } \\
\text { (tampilan/interface, } \\
\text { navigasi, penggunaan } \\
\text { controller, dsb)? }\end{array}$ & 52 & 28 & 18 & 2 & 0 \\
\hline 2. & $\begin{array}{l}\text { Seberapa puaskah anda } \\
\text { dengan aplikasi media } \\
\text { informasi gedung dan } \\
\text { ruang berbasis VR? }\end{array}$ & 50 & 40 & 8 & 2 & 0 \\
\hline $\begin{array}{l}\mathbf{N} \\
\mathbf{0}\end{array}$ & $\begin{array}{l}\text { Aspek Komunikasi } \\
\text { Visual }\end{array}$ & 5 & 4 & lam & 2 & 1 \\
\hline 3. & $\begin{array}{l}\text { Menurut penilaian } \\
\text { anda } \\
\text { bagaimana tampilan } \\
\text { visual pada gedung } \\
\text { dan } \\
\text { visualisasi pada } \\
\text { aplikasi } \\
\text { VR? }\end{array}$ & 48 & 50 & 2 & 0 & 0 \\
\hline 4. & $\begin{array}{l}\text { Menurut anda, } \\
\text { bagaimana } \\
\text { tampilan visual pada } \\
\text { interior ruang tiap } \\
\text { lantai gedung dan } \\
\text { visualisasi pada } \\
\text { aplikasi } \\
\text { VR? }\end{array}$ & 44 & 41 & 10 & 5 & 0 \\
\hline 5. & $\begin{array}{l}\text { Menurut anda, } \\
\text { bagaimana } \\
\text { informasi gedung } \\
\text { yang } \\
\text { telah diberikan pada } \\
\text { aplikasi VR? }\end{array}$ & 50 & 38 & 10 & 2 & 0 \\
\hline 6. & $\begin{array}{l}\text { Menurut anda, } \\
\text { bagaimana } \\
\text { informasi ruang yang } \\
\text { ada } \\
\text { pada tiap gedung } \\
\text { yang } \\
\text { telah diberikan pada } \\
\text { aplikasi VR? }\end{array}$ & 50 & 38 & 12 & 0 & 0 \\
\hline
\end{tabular}

Tanggapan 5:Sangat Baik, 4:Baik, 3:Cukup baik, 2:kurang Baik, 1: Tidak Baik

\subsection{Perbandingan Hasil Penelitian dengan Penelitian Terkait Sebelumnya}

Dari Penelitian sebelumnya (Zikky, 2016), dikembangkan sebuah aplikasi VR untuk wisata salah satu Kampus di Surabaya. Aplikasi ini menggunakan permodelan 3D yang dikembangkan dengan teknologi VR SDK Google di Unity. Sensor gyroscope yang digunakan dalam melakukan pergerakan tidak dapat membantu player agar dapat berpindah tempat. Oleh karena itu untuk membantu player agar bisa berpindah (melakukan translasi kedepan, mundur, dan geser kiri/kanan), maka dalam penelitian tersebut digunakan perangkat kontrol bluetooth joystick.

Pada penelitian yang kami lakukan ini, pergerakan dari berpindahnya player pada satu posisi ke posisi lainnya tidak menggunakan perangkat kontrol bluetooth joystic, melainkan dengan menggunakan pengaturan arah pandang dari fungsi gyroscope.

\section{KESIMPULAN}

Kesimpulan dari hasil penelitian yang telah dicapai adalah Aplikasi VR pada mobile dapat membantu memberikan informasi gambaran gedung, ruangan, dan fasilitas yang sangat baik berdasarkan aspek rekayasa perangkat lunak dan komunikasi visual masing-masing sebesar $51 \%$ dan $48 \%$. Hal ini terbukti dari interpretasi jumlah skor dari hasil evaluasi terhadap 100 responden dari 6 pertanyaan yang diajukan. Pergerakan posisi player dengan memanfaatkan fungsi gyroscope dibandingkan dengan penggunaan kontrol bluetooth joystic menyebakan aplikasi menjadi lebih imersif. Untuk penanganan konten dinamis dapat ditanggani dengan file JSON, dimana lebih ringan dibanding menggunakan database.

\section{UCAPAN TERIMA KASIH}

Ucapan terima kasih diberikan kepada Direktorat Riset dan Pengabdian Masyarakat Direktorat Jendral Penguatan Riset dan Pengembangan Kementrian Riset, Teknologi, dan Pendidikan tinggi atas pembiayaan penelitian ini melalui hibah dosen pemula tahun 2018.

\section{DAFTAR PUSTAKA}

DIMAS A.P. 2017. Implementasi Pengendalian Quadcopter Dengan Prinsip Virtual Reality Menggunakan Google Cardboard. Jurnal Pengembangan Teknologi Informasi dan Komputer. Vol. 1, No. 12: 1451-1458

FIRLY W. 2017. Pengembangan Permainan Edukasi Simulasi Astronomi Menggunakan Teknologi Mobile Virtual Reality. Jurnal Pengembangan Teknologi Informasi dan Komputer.Vol. 1, No. 11: 1185-1194

RIO FIORIDO PANGGABEAN. 2016. Rancang Bangun Peta Virtual 3D Kampus Untan Dengan Fitur Panorama $360^{\circ}$ x $180^{\circ}$. Jurnal Sistem dan Teknologi Informasi.Vol 4, No. 2: $174-179$

FRANCISCO TIGRE MOURA. 2017. Telepresence: The Extraordinary Power of Virtual Reality [internet]. Tersedia pada: $<$ https://musicstats.org/telepresenceextraordinary-power-virtual-reality/> [Diakses 3 Juni 2018]

Google Cardboard, 2014. Buy cardboard - Google VR. [Online]. Tersedia pada: <https://vr.google.com/intl/id_id/cardboard/ get-cardboard/> [Diakses 11 Juni 2018].

HENDRO TRIEDDIANTORO PUTO. 2015. Kajian Virtual Reality, Makalah Studi 
76 Jurnal Teknologi Informasi dan Ilmu Komputer (JTIIK), Vol. 6, No. 1, Februari 2019, hlm. 71-76

Mandiri: Universitas Teknologi

Yogyakarta, Januari 2015.

JEFKINS, FRANK. 1997. Periklanan. Jakarta: Erlangga

MOH. ZIKKY. 2016. Pengembangan Wisata Virtual Reality di Kampus PENS menggunakan Google Cardboard dan Smartphone Android. Seminar Nasional Teknologi Terapan. Oktober

PIUS D.W.A. 2017. Kajian Interaksi Pengguna untuk Navigasi Aplikasi Prambanan VR berbasis Virtual Reality. Junarl Teknologi Informasi dan Ilmu Komputer (JTIIK). Vol 5, No.2: 239-246 